Illinois State University

ISU ReD: Research and eData

Theses and Dissertations

3-22-2021

\title{
Understanding Teacher-Child And Peer Interactions During A 12-Week Preschool Art Program
}

Rebecca Bove

Illinois State University, boverebecca156@gmail.com

Follow this and additional works at: https://ir.library.illinoisstate.edu/etd

Part of the Developmental Psychology Commons

\section{Recommended Citation}

Bove, Rebecca, "Understanding Teacher-Child And Peer Interactions During A 12-Week Preschool Art Program" (2021). Theses and Dissertations. 1353.

https://ir.library.illinoisstate.edu/etd/1353

This Thesis is brought to you for free and open access by ISU ReD: Research and eData. It has been accepted for inclusion in Theses and Dissertations by an authorized administrator of ISU ReD: Research and eData. For more information, please contact ISUReD@ilstu.edu. 


\section{UNDERSTANDING TEACHER-CHILD AND PEER INTERACTIONS DURING A 12- WEEK PRESCHOOL ART PROGRAM}

\section{REBECCA BOVE}

58 Pages

Children's social and emotional development is essential for well being (Garner \& Estep, 2001). Prior research has examined the impact of teacher-child interactions on children's school adjustment, but little research has been done to explore how certain behaviors children demonstrate with teachers influence peer interactions (Graves Jr. \& Howes, 2011; Rudasill et al., 2013). The goal of the study was to examine whether the proportion of interactions and the positive or negative connotation of the interactions that a child had with teachers had an impact on social-emotional relations with peers. Using archival observational data collected while children participated in a 12-week art education program, I focused on teacher interactions, including (a) the proportion of positive engagement and guided instruction combined and (b) the proportion of non-compliance. Peer interactions were also analyzed with respect to (a) the proportion of working together and helping combined and (b) the proportion of conflict. It was hypothesized that teacher-child interactions in the fall would predict peer interactions in the spring. It was also hypothesized that peer interactions in the fall would predict peer interactions in the spring. Lastly, gender differences were hypothesized when examining teacher-child and peer interactions. As expected, negative peer interactions in the fall predicted negative peer interactions in the spring. Significant correlations were also found among some of the proportional measures. The findings provided insight about the stability of negative peer 
interactions for young children. Future studies should examine the impact these negative peer relations have on children as they develop.

KEYWORDS: teacher-child interactions, peer interactions, positive engagement, guided instruction, working together, preschool 
UNDERSTANDING TEACHER-CHILD AND PEER INTERACTIONS DURING A 12-

WEEK PRESCHOOL ART PROGRAM

REBECCA BOVE

A Thesis Submitted in Partial

Fulfillment of the Requirements

for the Degree of

MASTER OF SCIENCE

Department of Psychology

ILLINOIS STATE UNIVERSITY

2021 
(C) 2021 Rebecca Bove 
UNDERSTANDING TEACHER-CHILD AND PEER INTERACTIONS DURING A 12-

WEEK PRESCHOOL ART PROGRAM

REBECCA BOVE

COMMITTEE MEMBERS:

Julie Campbell, Chair

Alycia M. Hund

Corinne Zimmerman 


\section{ACKNOWLEDGMENTS}

I wish to show my appreciation to my committee chair, Dr. Julie Campbell, and members, Drs. Alycia Hund and Corinne Zimmerman, whose assistance was a milestone in the completion of this project. I wish to also show my appreciation to Illinois Art Station whose dedication in helping bring visual arts to children inspired the idea for this project.

Thank you to my family, my parents, Jim and Angela Bove, for your encouragement and belief in me, and to my friends. And last, a special thank you to my roommates, Liv and Liz, for without your love and support, none of this would be possible. I love and appreciate you all.

R. M. B 


\section{CONTENTS}

Page

ACKNOWLEDGMENTS

CONTENTS

$\begin{array}{ll}\text { TABLES } & \text { iii }\end{array}$

$\begin{array}{lc}\text { INTRODUCTION } & 1\end{array}$

CHAPTER I: INTRODUCTION OF KEY ELEMENTS 1

Social-Emotional Development 1

Teacher-Child Interactions and Social Learning Model $\quad 7$

Teacher-Child Interactions and Social-Emotional Development 8

Peer Interactions and Social-Emotional Development 13

$\begin{array}{ll}\text { Peer Interactions } & 16\end{array}$

Teacher-Child Interactions in Regard to Peer Behaviors 16

Gender Differences in Teacher-Child and Peer Interactions 18

Teacher-Child and Peer Interactions and School Adjustment 19

Understanding Teacher-Child and Peer Interactions $\quad 21$

$\begin{array}{ll}\text { Research Questions } & 21\end{array}$

$\begin{array}{ll}\text { CHAPTER II: METHOD } & 24\end{array}$

$\begin{array}{ll}\text { Participants } & 24\end{array}$

$\begin{array}{ll}\text { Materials } & 24\end{array}$

Social and Emotional Development $\quad 24$

$\begin{array}{ll}\text { Peer Interactions } & 24\end{array}$

Teacher Interactions 25 
CHAPTER III: RESULTS

REFERENCES

APPENDIX A: TABLES

APPENDIX B: FIGURES 


\section{TABLES}

Table

Page

1. Coding Categories for Peer Interactions

2. Coding Categories for Child-Teacher Interactions 


\section{CHAPTER I: INTRODUCTION OF KEY ELEMENTS}

Social-emotional development not only affects children's ability to relate to others and their ability to process emotions, but also their executive function, language, physical development, and other cognitive abilities (Greene \& Sawilowsky, 2018). Educational programs allow children to form relationships with their teachers that in turn help children with peer interactions (Howes, Hamilton, \& Matheson, 1994). Children learn skills such as turn taking and inhibition when participating in educational programs (Immordino-Yang, et al., 2019).

Educational programs bring about teacher-child interactions that in turn impact peer relations.

\section{Social-Emotional Development}

Social interactions with peers are part of young children's development. Young children not only interact with their parents and siblings, but other children their age. Social development is important, and different skills help to build these social relationships. Children who have a basic knowledge of the language and norms of their peers are more likely than others to participate in activities with their peers (Katz \& McClellan, 1991). When children interact with others, social understanding and skills are needed to maintain these relationships. During social interactions, children learn how to communicate, discuss, negotiate, take turns, cooperate, and empathize (Katz \& McClellan, 1991). Socially skilled young children are able to synchronize themselves with others by establishing common ground, exchanging information, and exploring similarities and differences, while at the same time resolving conflicts during play (Katz \& McClellan, 1991). All these skills take time and effort to develop in children.

Some children may take longer than others to develop social skills, which can lead to interpersonal difficulties. Young children may not have the impulse control to interact with their peers in an appropriate way when it comes to conflict (Katz \& McClellan, 1991). Katz and 
McClellan (1991) also mention other difficulties that come with lagging social development including the lack of knowledge of and experience with the give and take of peer interaction. Some other children may not have enough confidence to succeed in dynamic interplay with peers. The causes of these social difficulties can vary widely. When it comes to peers, children may lack the appropriate skills and the opportunities to learn and practice them (Katz \& McClellan, 1991). Katz and McClellan (1991) go on to say that what may be appropriate for a two- or three-year-old in regards to how much time spent in parallel or solitary play, maybe is less appropriate for a five-year-old. They conclude that research indicates that if 5-year-olds work or play alone it is because they lack the understanding and skills required for achieving a satisfying interaction with other children.

Emotional development is another essential part of successful development. Improvements in emotional development aids in social development. Children's ability to label and manage different emotions provides them with skills such as talking through their feelings instead of acting out (Raver, 2002). With emotional development comes emotion regulation-the internal and external processes responsible for evaluating and monitoring emotional reactions (Thompson, 1991). Emotion regulation leads children to have other skills such as the ability to process changes. Emotion regulation processes provide flexibility to the behavioral processes that emotions control. They also enable someone to respond quickly and efficiently to changes in their environment (Thompson, 1991). This growth of emotion regulation is a significant part of emotional development. It is significant because a child's emotions are managed externally and are being self-regulated as they develop. Emotional experiences become socialized and acquire new meaning for the child. These emotions can be controlled by the child and used in different ways and can thus be integrated into the child's growing repertoire of different strategies for 
behavioral interactions (Thompson, 1991). An understanding of emotion regulation provides a way to see the individual differences in personality and social functioning (Thompson, 1991). Emotion regulation plays an important part in emotional development by helping with selfcontrol and the growth of an individual's personality and social functioning with others. Emotional development helps children understand their emotions, use self-control, and form social relationships with their peers.

Social-emotional skills are a vital aspect of young children's development. These skills are strong indicators of success in many different aspects of life (Greene \& Sawilowsky, 2018). Social-emotional learning can be described as the developing capability of a young child to be confident, to have the ability to develop relationships with peers and adults, to demonstrate attentiveness and persistence on challenging tasks, to effectively communicate emotions, to listen to instructions and be attentive, and to solve social problems (Leggett \& Ybañez-Llorente, 2016). Brouillette (2010) also describes social-emotional development as a child's experience and management of emotions, as well as their ability to establish positive and rewarding relationships with others. Early childhood social-emotional development provides the foundation for health and social welfare. It also provides prevention of psychopathology throughout childhood and into adulthood (Davis et al., 2016). Social-emotional development plays an important role in how a child grows and learns. Leggett and Ybañez-Llorente (2016) state that social and emotional development in early childhood is an essential building block to learning successful ways to reason, make decisions, solve problems, and experience well-being, leading to current and later successes.

Many children spend an increasing amount of time in educational settings from an early age. It is important to examine social-emotional development in these settings. Multiple studies 
have attempted to examine social-emotional development in an educational setting. Garner and Estep (2001) investigated links between aspects of emotional competences and preschoolers' social skills with peers in a school setting. To do this, Garner and Estep (2001) observed 82 preschool participants and their mothers. Peer observations and social cognitive assessments of the children were conducted while the children were at preschool. They found that children's explanations of the causes and consequences of emotions were a positive predictor of social skills and emotional competence. Children also used emotional discourse, expressing emotions while talking, to negotiate conflict. Garner and Estep (2001) also found that the level of positive emotional expression during peer play was positively related to social initiations and the frequency with which children were chosen as the targets of positive social bids from peers. Overall, this study provides a foundational look at how emotional competence and emotion socialization contribute to peer behavior and the importance of designing and implementing affective intervention programs for young children and their families. Intervention programs for children who struggle with emotional competence and socialization could focus on ways to negotiate conflict with peers or how to increase the frequency of positive emotional expressions when engaging with peers.

Garner and Estep (2001) state children who are rated high in emotional knowledge have more positive peer interactions and are better liked by their peers. Children, in this sample, were better with expressive and emotional cues. That is, the children who were able to use expression more effectively and were more aware of social cues, were better able to process thoughts and feelings of others (Garner \& Estep, 2001). Social-emotional development is critical in the process of making friends and figuring out how to engage with others. Empathy, sharing, cooperative play, patience, turn taking, conflict resolution and properly dealing with anger are all 
important skills that help-children succeed in peer relationships, schooling, and self-regulation (Immordino-Yang, et al., 2019). Each of these factors separately relate to social-emotional development. Skills such as empathy and patience show social and emotional development (Immordino-Yang, et al., 2019). Children can learn about sharing, turn taking, cooperative play, and conflict resolution through empathy and patience.

Other research has examined social competence and emotional maturity. Janus, Duku, Brinkman, Dunkelberg, Chianca, and Marino (2014) examined social-emotional development in a sample of native preschool children from Peru and Brazil who were 4 to 6 years of age. Janus et al. (2014) examined a teacher-completed measurement of child development status, the Early Development Instrument (EDI), in three communities. The EDI consisted of two domains: social competence and emotional maturity. Social competence includes four subdomains: overall social competence, approaches to learning, responsibility and respect, and eagerness to explore new things. The emotional maturity domain includes four subdomains: anxiety, aggression, hyperactivity, and prosocial behavior. Overall, Janus et al. (2014) found that children's approach to learning (e.g., ability to work independently and cooperate with others, follow routines, and adjust to change) was associated with children's social competence.

The previous example highlights the relation between educational factors, such as a child's approach to learning, and social competence. Other studies have also examined the relation between social-emotional skills and school readiness, for example Denham, Bassett, Mincic, Kalb, Way, Wyatt, \& Segal, 2012. The sample included 364 children recruited at Head Start and private childcare centers. Children's social-emotional learning (SEL) measures were collected in fall to early spring of the year before kindergarten; with each direct assessment performed on different days within an approximately three-month period, and observations made 
on four separate days within this period. Preschool teacher measures were collected at the end of the school year. Measures of preschoolers' social and emotional competence included the Affect Knowledge Test (AKT), Preschool Self-Regulation Assessment (PSRA), Social problemsolving: Challenging Situations Task, and Observed affect and behavior: Minnesota Preschool Affect Checklist Revised and Shortened (MPAC-R/S). Teacher measures included Preschool Learning Behavior Scale (PLBS), Social Competence and Behavior Evaluation (SCBE-30), Academic success: ECLS-K Academic Rating Scale, and Student-Teacher Relationship Scale (STRS). Denham et al. (2019) found that three groups were identified: SEL Risk, SEL Competent-Social/Expressive, and SEL Competent-Restrained. Group members differed on demographic dimensions of gender and center type, and groups differed in meaningful ways on school success indices, pointing to needed prevention/intervention programming. The SEL Risk group showed significantly lower emotion knowledge and self-regulation compared to the other groups. The SEL Competent-Social/Expressive group showed significantly more adaptive social problem solving and greater evidence of mature social and emotional behaviors. The SEL Competent-Restrained group differed in terms of their social problem-solving patterns. It was clear that the SEL Risk group had a less developed understanding of emotions, had more trouble effortfully controlling their behavior and complying with the examiner, and already used angryaggressive social problem-solving patterns, along with only moderate emotional positivity and productive play. Denham et al. (2019) suggested that difficulty in understanding and identifying emotions, an angry-aggressive pattern of social problem-solving, and negative emotional expressiveness were three features characterizing children in the SEL Risk group. As such, programs that focus on emotions and their effective utilization, as well as social problemsolving, may be useful for assisting children in the development of their social emotional 
knowledge. Together, these studies have demonstrated a strong relation between emotional competence and peer behavior and other skills that are beneficial for children in school such as conflict resolution and turn taking.

\section{Teacher-Child Interactions and Social Learning Model}

Teachers can shape the overall psychosocial development of children during the preschool period. Bandura's social learning theory, which describes the role of social learning or learning by model, can represent the work teachers do with their students (Bandura, 1976). The role of teachers and the application of the social learning theory can significantly improve the educational process (Raičevič, Nikolic, Vlasta, \& Saračevič, 2017). Raičevič et al. (2017) explained that modeled behaviors can be adopted in childhood and may be used for the purpose of encouraging the positive and suppressing the negative behaviors. In addition, through appropriate modeled behaviors from teachers, children can improve their social skills and abilities (Raičevič et al., 2017). When it comes to social-emotional skills, teachers who have well-developed social-emotional skills will represent an appropriate role model for children and will be able to adequately encourage the development of these characteristics in children, through a process of social learning (Raičevič et al., 2017). Teachers are also largely responsible for showing by example and fostering a positive climate in the classroom in which social learning can become an inclination between the teacher and the children (Raičevič et al., 2017). Bandura's theory also talks about status when it comes to social learning processes. Within any social group, some members are likely to command greater attention than others (Bandura, 1976). The status of the model is highly influential in determining which models will be closely observed and which will be ignored. Since teachers hold a high status in schools, children are more likely to model their behaviors over their peers. Overall, social learning processes 
presented by teachers and the status of teachers are important mechanisms by which children learn appropriate social behaviors.

\section{Teacher-Child Interactions and Social-Emotional Development}

Teacher-child interactions are important for children to learn social and emotional regulation skills. Farmer, Lines, and Hamm (2011) examined the role of the teacher in children's

peer experiences. The interactions students have with their teachers set the context for the type of relationships students are expected to have with each other. Studies suggest that students' social competence, academic engagement, and emotional development are related to the warmth and emotional sensitivity their teachers demonstrate in the classroom (Famer et al., 2011). In addition to the relationship that teachers form with students in general, teachers also develop distinct relationships with individual students. Children who engage in problem behaviors are more likely to have difficult relationships with their teachers compared to children who do not engage in these problem behaviors (Famer et al., 2011). Teachers form relationships with children while engaged in being a classroom leader. Teachers have the opportunity to manage classroom interactions, promote productive engagement of all students, and help students who struggle with their social skills to develop new roles or identities (Famer et al., 2011). Farmer et al. (2011) concluded that teachers are the one professional in a child's life who have the opportunity to view the whole child and to see the different contributions of academic, behavioral, physical, and social domains in relation to the social climate. Teachers can consult with intervention specialists to identify strategies to address the needs of specific students and the broader classroom. Overall, Farmer et al. (2011) revealed the role teachers play in the social development of their students and the connections they make with their peers. 
While Farmer et al. (2011) was able to bring to light the unique role that teachers have in the social development of their students, Howes et al. (1994) focused on the how teacher-child relationships help with peer relationships. Specifically, they examined children's relationships with peers and the association of these peer relationships with the child-teacher relationship. Children that are enrolled in child-care have multidimensional relationships with their teachers. Child-care teachers' roles in the lives of the students can be differentiated into three distinct aspects: security, dependence, and socialization. The ideal child-care teacher provides children with a learning environment that not only is rich in language and cognition but helps children form trusting relationships with adults and positive peer interactions (Howes et al., 1994). Howes et al. (1994) go on to explain that adult managed peer contacts and interactions are important for socialization experiences.

In a longitudinal study, Howes et al. (1994) hypothesized that early positive teacher socialization would predict peer competence. They observed 48 children over a 3-year period. Children ranged in age from 13 to 24 months at the first data collection period. Howes et al. (1994) used the Waters and Deane (1985) Attachment Q-Set to assess teacher-child relationship quality. They collected Q- sort behavior sample data on the children across six time points approximately 6 months apart. The behavioral data collection consisted of times when the child was free to interact with adults and peers. Only the peer behaviors, which were collected when the children were 4 years old, were used in the analysis. During the final observation, the child was interviewed, and teachers completed a Likert-like rating scale for 16 dimensions of the child's functioning with peers. Howes et al. (1994) found that child-teacher security scores positively predicted three dimensions of competent peer behavior: prosocial, gregarious, and complex play. Child-teacher security negatively predicted two dimensions of maladaptive 
behavior with peers—hostile aggression and withdrawn behaviors. The results suggest that these child-teacher relationships are associated with peer social competence. Teacher-child relationships appear to be multidimensional, and different aspects of the teacher-child relationships appear to be differentially associated with the developmental of social competence with peers at different developmental domains. Overall, Howes et al. (1994) found that teacherchild relationships help young children develop social competence later with peers.

Research has consistently demonstrated that teacher-child relationships are associated with early school adjustment (Graves Jr. \& Howes, 2011; Rudasill, Niehaus, Buhs, \& White, 2013). Teachers' relationships with their students have an impact on how the students behave in the classroom. Specifically, teacher-child relationships that are high in closeness are associated with reduced problematic behavior and increased prosocial competence (Graves Jr. \& Howes, 2011). A study done by Graves Jr. and Howes (2011) examined the effects of classroom and teacher variables on social-emotional development in prekindergarten. Graves Jr. and Howes (2011) examined one research question which asked: What classroom and teacher factors are significantly related to prekindergarten children's behavior problems? They used data from the National Center for Early Development and Learning (NCEDL) Multi-State Study of Prekindergarten, and a follow-up study, the State-Wide Early Education Programs Study (SWEEP). The final sample in the analysis consisted of 2,898 children. Student-teacher relationships were assessed by teachers reporting on the quality of their relationships with students by completing the Student-Teacher Relationship Scale.

Graves Jr. and Howes (2011) found that teacher-child conflict and fall ratings on socialemotional development were significant and consistent predictors of teacher-rated conflict problems, peer social skills, and frustration tolerance. Specifically, the way in which teachers 
perceived children's behavior during the fall of prekindergarten and the conflict or lack thereof that teachers and students experienced were important factors in the reduction and prevention of conduct problems according to teachers. These findings provide an opportunity to develop interventions which focus on problems such as conflict in the classroom that could be seen later in the educational system before behavior issues reach critical junctures. It is also important to examine the factors over time.

Rudasill et al. (2013) examined temperament in early childhood and peer interactions and the role of teacher-child relationships. Past studies found that teacher-child conflict in preschool was a significant and negative predictor of teacher-rated social competence with peers in second grade (Rudasill et al., 2013). Studies also mentions that other research has found that teachers' negative feedback was linked to poorer peer interactions (Rudasill et al., 2013). The study done by Rudasill et al. (2013) wanted to expand existing research exploring the extent to which children's relationships quality with teachers in kindergarten through second grade moderates and mediates links to peer interactions such as aggression, relational aggression, peer victimization, and prosocial interactions. Participants were drawn from the national Institute for Child Health and Human Development Study of Early Child Care and Youth Development (NICHD SECCYD). The sample included 1,364 participants composed of 704 boys and 659 girls. Rudasill et al. (2013) included teacher-child relationship quality and peer interactions as their measures. Teacher-child relationship quality was assessed using teachers' responses on the Student-Teacher Relationship Scale. Peer interactions were assessed by teachers using a 43-item questionnaire adapted by the NICHD SECCYD from the Child Behavior Scale. Rudasill et al. (2013) found children's difficult temperament was positively associated with teacher-child conflict. Teacher-child relationship quality did not moderate linkages between difficult 
temperament and peer interactions. Teacher-child conflict, but not closeness, mediated associations between difficult temperament and all four peer interaction variables which consisted of aggression, relational aggression, peer victimization, and prosocial interactions. Children's relationships with their teachers are a source of social support that are associated with school adjustment and linked to the quality of children's interactions with peers (Rudasill et al., 2013). These findings add to emerging research examining the associations between the teacherchild relationship and children's peer interactions.

Teacher-child interactions should also be examined over time. A study done by O'Connor, Dearing, and Collins (2011) examined the teacher-child relationship and problem behavior trajectories. Teacher-child relationships are built within the school system. High-quality relationships with teachers help children's self-regulatory and social development skills. They have been found to be related to lower levels of externalizing and internalizing behavior problems (O'Connor et al., 2011). O'Connor et al. (2011) explain that within these high-quality relationships with teachers, children are likely to form positive working models that encourage them to seek out supportive interactions and engage in age-appropriate behaviors with others. In the present study, O'Connor et al. (2011) examined associations between the quality of teacherchild relationships and behavior problems among elementary school students. The study was conducted using data from the NICHD Study of Early Child Care and Youth Development. The sample consisted of 1033 children, and data collection happened when the children were in first, third, and fifth grade. The 15-item Student Teacher Relationships Scale was used to assess teacher perceptions of the quality of the teacher-child relationship at first, third, and fifth grade. Using a 5-point Likert-type scale that ranges from 1 to 5, teachers rated how applicable statements are to their current relationship with a particular child. Two features of the 
relationship were studied: closeness and conflict. The closeness subscale is an index of the amount of warmth and open communication present in the relationship, and the conflict subscale measured the extent to which the relationship was marked by antagonistic, disharmonious interactions. The Classroom Observation System was used to assess the positive emotional climate of the child's classroom at first, third, and fifth grade. Trained observers visited the child's classroom and observed both the classroom and the study child. Coders rated classroom environment which included teacher responsiveness and how the children engaged in interactions with one another. O'Connor et al. (2011) found that high-quality teacher-child relationships predicted low levels of externalizing behaviors. They also found that high-quality relationships acted as protective factors, helping to prevent children with high levels of internalizing behaviors in early childhood from developing trajectories of long-term internalizing behavior problems. These findings can help target teacher-child relationships for interventions to help prevent problems behaviors later in school.

\section{Peer Interactions and Social-Emotional Development}

Peer interactions play a role in the social-emotional development of young children. One way for children to have these peer interactions is through play. During the early years of the child study movement, a number of researchers investigated the play behaviors of young children. Parten (1932) defined six sequential social participation categories: unoccupied behavior; solitary play; onlooker behavior- observes other children but does not participate in the activity; parallel play- plays besides but not with other children; associative play- plays and shares with others; and cooperative play- social play in which there is defined division of labor. Parten (1932) concluded that as children grow older, they engage in more associative and 
cooperative play and less idle, solitary, and onlooker behavior. Piaget's (1962) play categories were labeled as follows: functional play, constructive play, dramatic play, and games with rules.

Rubin (1977) examined play behaviors in young children and reported the results of a series of studies in which the relationship between the social play hierarchy of Parten (1932) and the cognitive play hierarchy of Smilansky (1968) was investigated. Rubin (1977) examined the free play of 40 four-year-old children. Each child was observed one minute per day on 30 consecutive school days by two observers. During the observation period, the number of seconds each child engaged in a particular form of cognitive play within each social play category was coded. After each one-minute observation, the observers recorded exactly what it was the children were doing and with whom. It was found that lower SES children in this group were significantly more likely to engage in functional and parallel play, and were significantly less likely to engage in associative, cooperative, and constructive play than their middle SES agemates. Rubin et al. (1977) concluded that lower SES children attending this preschool were less mature, both socially and cognitively, in their play styles than their middle SES age-mates. It was also found that lower SES children displayed significantly more solitary- and parallel-functional play, and less associative-constructive and cooperative-dramatic play than middle SES agemates. Based on these findings, one could interpret that children with lower SES engage in different kinds of play because of the different resources available.

Bar-Tal, Raviv, and Goldberg (1982) examined helping behavior among preschool children in an observational study. The present study wanted to extend the investigation of children's helping behavior to early childhood by observing the circumstances and the conditions that determined the quality of their helping behavior. The study also investigated various forms of helping behavior exhibited by children. Bar-Tal et al. (1982) defined helping behavior as an 
act which benefits others, and no prior promise of a tangible reward has been given in return. They broke down helping behaviors into four categories: sharing- donating part of the object or objects in the individual's possession to another person; giving- donating the whole of the object in the individual's possession to another person without leaving any for oneself; aiding- the alleviation of another's non-emotional needs through verbal or motor behavior; and comfortingthe alleviation of emotional needs of another, verbally or physically. The sample consisted of 156 children with the average age being around 3-years old. The children were divided into age groups for the analysis. Each child was observed by two observers from 10 minutes during free play activity, on three separate occasions. During the free play activity, the children were free to move outdoors and indoors and chose any activity or game they wanted. The observations were made as discreetly as possible, with little disturbance to the child's activity. Each observer carried a clipboard with data sheets to code the observations. As soon as the observers completed their 10-min observation of one child, they immediately went on to the next child on their list. During the 10-min observation, the observers were instructed to record the frequencies of social contacts the child made. The behavior of each child was coded in different categories. The categories were social contact-which was whenever a child was in company or approached another person or persons or was approached to play, to talk, or to listen. The observes noted whether the contact was made with a teacher or a peer. Helping act- which was whenever a child performed an act which benefited another person, even when a reward was promised in advance. The observers then categorized the helping act into either sharing, giving, aiding, or comforting. Bar-Tal et al. (1982) found that children in the youngest age group had more social contacts with a teacher than any other age group. They also found that the proportion of real helping acts, helping acts that are performed to the real needs of another and not during dramatic play, to total 
helping acts was found to increase significantly with age. Based on these findings, one could interpret that social contacts with a teacher decrease with age and helping acts increase with age.

\section{Peer Interactions}

Young children influence each other. Past studies have found that peer play represents a primary context in which preschool children acquire and express peer social competencies (Coolahan, Fantuzzo, Mendez, \& McDermott, 2000). The repeated exposure to these peer interactions during play, especially those involving prosocial behavior or aggressive encounters, are important experiences that impact children's social development (Coolahan et al., 2000). Barth, Dunlap, Dane, Lochman, and Wells (2004) examined classroom environment influences on aggression and peer relations. They found that fourth graders with high ratings for aggression had a greater increase in problematic behaviors if they were placed in a fifth grade classroom also rated high on aggression. Another study examined the affiliation/shaping model, which hypothesizes that children actively seek out and affiliate with peers similar to themselves, and that child behavior is subsequently shaped in a very powerful manner within these close affiliative relationships. Based on this hypothesis, it could be expected that aggressive children would affiliate with similarly aggressive peers and that these peer relationships model aggressive behaviors (Snyder, Horsch, \& Childs, 1997). Overall, young children model behaviors exhibited by their peers. As such, peer interactions influence young children's social development.

\section{Teacher-Child Interactions in Regard to Peer Behaviors}

How children interact with their teachers can influence how they will interact with their peers (Famer et al., 2011). One way for children to interact with their teachers in through play. When it comes to play, teachers can adjust the attention they are giving based on the need of each child (Wilcox-Herzog \& Kontos, 1998). Trawick-Smith and Dziurgot (2011) wanted to test 
a model of adult-child play interaction in preschool classrooms, based on the work of Vygotsky and neo-Vygotskian scholars. The model predicts that adults will tailor the play support they provide to the immediate needs of the individual children, and that this will lead to subsequent independent play. Participants were eight early childhood education professionals who taught in two full-day preschool classrooms. Data was gathered from two primary sources. Adult participants were video recorded during four or five 30-minutes observations over a 20 -week period as they interacted naturally with children during free-play periods in the classroom. Each adult participant was also interviewed in two separate one-hour sessions, one at the beginning and one near the conclusion of the study. In addition to the video recordings and interviews, data from a number of secondary sources were gathered such as general observations of classroom activities and routines to acquire an overall picture of classroom life and to determine when, where, and for what duration play opportunities were provided. Video recordings were transcribed, and specific units of child and teacher behavior that were related to the study were identified. A unit of behavior was defined as a verbal or nonverbal action within an adult-child play interaction. Child play needs and teacher responses to play needs were identified. Child play needs included much need, some need, and no need. Play behaviors that were categorized as much need or some need could be further sorted into seven types of need such as social conflicts. Social conflicts were play in which a child was unable to resolve a disagreement with a peer or engaged in play that is aggressive, otherwise anti-social, and/or threatens positive peer relations. Teacher responses to play need included four distinct levels of guidance: direct, indirect, observations, and no interaction. Direct guidance was a response to a play behavior in which an adult asked, demanded, physically guided, or in other ways prompted a child to behave in a certain way. Indirect guidance was a response to a play behavior in which an adult guided and/or 
enhanced a child's activity, without demanding or imposing a specific play action. TrawickSmith and Dziurgot (2011) found that teachers responded to children's play behaviors with good-fit interactions and that these interactions lead to more independently subsequent play. Overall, the study contributes to a growing body of research suggesting that the quality of teacher-child interactions can be critical component for supporting children's development in early educational programs.

\section{Gender Differences in Teacher-Child and Peer Interactions}

Gender differences are another important aspect of teacher-child interactions and classroom behavioral adjustment. Ewing and Taylor (2009) examined the role of gender in teacher-child relationship quality and children's behavioral adjustment in preschool. They stated that past studies of children's peer interactions show that girls tend to be more cooperative in their interactions, whereas boys tend to be more focused on establishing dominance in their interactions. They also stated that other studies have found that teachers tend to have closer and less conflictual relationships with girls compared to boys. The purpose of the study by Ewing and Taylor was to build on the existing research by examining child gender as a moderator of the link between teacher-child relationship quality and children's school behavioral adjustment. A total of 301 children enrolled in Head Start classrooms and 25 teachers participated. Data for the study were collected as part of a larger longitudinal investigation. Teachers completed questionnaires about the quality of the teacher-child relationship and the child's school behavioral adjustment. Teacher-child relationship quality was assessed using the StudentTeacher Relationship Scale (STRS). The STRS contains 30 items designed to assess the teacherchild relationship on three quality: closeness, conflict, and dependency. Ewing and Taylor (2009) found that girls were rated higher than boys in teacher-child closeness and school competence, 
whereas boys were rated higher than girls with respect to aggression. Based on the results, teacher-child relationships may differ depending on the child's gender. It is important for teachers to monitor the emergence of early conflict in their relationships with boys and dependency with girls. Consistent with these findings, Baker (2006) found that girls experienced more closeness and less conflict with their teachers than did boys. Hamre and Pianta (2001) also found high levels of perceived conflict between the teacher and boys compared to girls. When it comes to peers, Howe and McWilliam (2001) found that boys display more dominance in arguments. Booren, Downer, and Vitiello (2012) also found that boys tended to be higher than girls in their peer conflict behaviors.

\section{Teacher-Child and Peer Interactions and School Adjustment}

In educational settings, students have different interactions with their teachers and peers. Williford, Maier, Downer, Pianta, and Howes (2013) examined how children's engagement and teachers' interactions combine to predict school readiness. The preschool classroom is an important context that provides learning experiences that help foster school readiness (Williford et al., 2013). Two aspects of the quality of children's preschool classroom experience that promote learning of academic and social-emotional skills are: (1) an individual child's engagement and interaction with the environment provided and (2) the teacher's capacity to provide a stimulating environment through their interactions with children (Williford et al., 2013). How children engage with teachers, peers, and learning activities in the classroom relates to school achievement and adjustment (Fredricks, Blumenfeld, \& Paris, 2004). The purpose of Williford et al. (2013) study was to illustrate the combined experiences of children's engagement and teacher interactions in preschool classrooms and how the quality of the preschool experience is linked with children's gains in school readiness skills. Data were collected as part of the 
National Center for Research on Early Childhood Education's Professional Development Study. A total of 325 teachers and 605 children participated. Teachers completed a professional and classroom demographic survey. Researchers completed direct child assessments and observations of teacher-child interactions at the classroom level and of children's individual classroom engagement. The Individualized Classroom Assessment Score System (inCLASS) was used to assess the quality of individual children's engagement within the preschool class. The inCLASS is an observational assessment of children's classroom engagement in interaction with teachers, peers, and tasks. It is composed of different dimensions: (1) positive engagement with teachers- attunement to the teacher, proximity seeking, and shared positive affect, (2) conflict with teachers- aggression, noncompliance, negative affect, and attention-seeking directed toward the teacher, (3) sociability with peers- proximity seeking, shared positive affect, popularity, perspective-taking, and cooperation, and (4) conflict with peers- aggression, confrontation, negative affect, and attention-seeking directed toward peers. Factor analysis of the dimensions identified three domains of child interactions: (1) positive engagement with teachers (positive engagement and communication with teachers); (2) positive engagement with peers (sociability, assertiveness, and communication with peers); and (3) negative classroom engagement (conflict with teachers and peers). School readiness was also examined through selfregulation and inhibitory control. Inhibitory control was assessed using the Pencil Tap Test which asked children to tap once when the assessor taps twice and vice versa. Williford et al. (2013) found that conflict with teachers and peers are highly related. They also found that both children's individual engagement and the quality of teacher-child interactions at the classroom level were uniquely predictive of children's school readiness skills. Children who were more positively engaged within the classroom (e.g., connecting positively to their teachers and being 
social and cooperative with peers) showed greater gains in their self-regulation skills. Children who were negatively engaged in the classroom (e.g., exhibiting conflict with teachers and peers) made fewer gains in their self-regulation skills. These findings indicate that preschool is a context where children can be exposed to early learning experiences that are important for them to form academic and social-emotional skills. Preschool is also a context where children can interact with their teachers and peers. Children who are positively engaged in the classroom may be more likely to have positive interactions with their teacher and peers.

\section{Understanding Teacher-Child and Peer Interactions}

The development of 3-, 4- and 5-year-old children involves rapid change in many areas of development. When it comes to social-emotional development, new skills are acquired every day. Children must learn how to interact with their peers in appropriate ways while controlling their emotions. With past research demonstrating teacher-child interactions influence how children interact with their peers (Howes et al., 1994), finding a connection between teacher and peer interactions could provide a better understanding of how certain behaviors children demonstrate with their teachers predict how they will interact with their peers in the future. The main goal of the thesis study was to examine whether the proportion of interactions and the positive or negative connotation of the interactions that a child had with teachers had an impact on social-emotional relations with peers.

\section{Research Questions}

(1) Do positive teacher-child interactions in the fall predict positive peer interactions in the spring? Are there differences by gender?

It was hypothesized that the proportion of positive teacher-child interactions, in the form of positive engagement and guided instruction with teachers in the fall, would predict the 
proportion of positive peer interactions, assessed as working together and helping peers, in the spring.

(2) Do negative teacher-child interactions in the fall predict negative peer interactions in the spring? Are there differences by gender?

It was hypothesized that the proportion of negative teacher-child interactions, in the form of non-compliance to teacher requests, in the fall would predict the proportion of negative peer interactions, assessed as conflict with peers, in the spring.

(3) Do positive peer interactions in the fall predict positive peer interactions in the spring? Are there differences by gender?

It was hypothesized that the proportion of positive peer interactions, in the form of working together and helping peers in the fall, would predict the proportion of positive peer interactions in the spring.

(4) Do negative peer interactions in the fall predict negative peer interactions in the spring? Are there differences by gender?

It was hypothesized that the proportion of negative peer interactions, in the form of conflict with peers in the fall, would predict the proportion of negative peer interactions in the spring.

(5) Are there gender differences in how children interact with both their teachers and peers?

It was hypothesized that girls would have more positive teacher-child interactions as positive engagement and guided instruction and positive peer interactions as working together and helping than would boys; and that boys would have more negative teacher- 
child interactions as non-compliance and negative peer interactions as conflict than would girls. 


\section{CHAPTER II: METHOD \\ Participants}

Observational data were collected from 68 children, ages 3 to 5 years old including 31 boys and 37 girls, 10 teachers from one preschool located in Bloomington-Normal, Illinois, and

five Illinois Art Station staff teachers. A power analysis using the G-power computer program (Erdfelder et al., 1996) indicated that a total sample of 95 children would be needed to detect small effects $(\mathrm{d}=.08)$ with $80 \%$ power using a $F$ test for linear regression with alpha at .05 . With a sample size of 68 children, we achieved $62 \%$ power using a $F$ test for linear regression with alpha at .05 and two predictors. The ages of the children were not collected during this study and in turn no analyses was done on the effects of age. The children and data were part of a larger program, organized by the Illinois Art Station, in which approximately 300 students participated each week. The Illinois Art Station provides free art classes to children in local schools via art education teachers. The population of the preschool center in this sample was diverse with regard to race/ethnicity (38.5\% White, 24.5\% African American, 18.2\% Hispanic, and 7.7\% Asian). The percentage of students at the preschool center receiving free and reduced lunch is $56.72 \%$.

\section{Materials}

\section{Social and Emotional Development}

Observational data were collected via live observations which were recorded as the children participated in the program. Social-emotional behaviors involving peer and teacher interactions were live coded using the Animal Behavior Pro app (adapted from Newton-Fisher, 2012).

\section{Peer Interactions}


Peer interactions that were coded include working together, helping, and conflict. Table 1 includes the operational definitions.

\section{Table 1}

Coding Categories for Peer Interactions

\begin{tabular}{|l|l|l|}
\hline Peer Interaction Type & Key Features & Observational/Behavioral Cues \\
\hline $\begin{array}{l}\text { Working together } \\
\text { (positive interaction) }\end{array}$ & $\begin{array}{l}\text { Child is engaging with } \\
\text { another child about task } \\
\text { by talking, observing } \\
\text { and copying. Interaction } \\
\text { appears bi-directional }\end{array}$ & $\begin{array}{l}\text { Two children are talking and } \\
\text { interacting while completing one } \\
\text { of the art tasks }\end{array}$ \\
\hline $\begin{array}{l}\text { Helping } \\
\text { (positive interaction) }\end{array}$ & $\begin{array}{l}\text { Child initiates or } \\
\text { volunteers to assist } \\
\text { another child with an art } \\
\text { task }\end{array}$ & $\begin{array}{l}\text { The child is helping another } \\
\text { child complete the art task by } \\
\text { giving art supplies or } \\
\text { demonstrating the task }\end{array}$ \\
\hline $\begin{array}{l}\text { Conflict } \\
\text { (negative interaction) }\end{array}$ & $\begin{array}{l}\text { Negative affect: crying, } \\
\text { pouting, refusing to } \\
\text { work } \\
\text { Contact aggression: } \\
\text { pinching, hitting }\end{array}$ & $\begin{array}{l}\text { The child could be fighting with } \\
\text { another child over art supplies }\end{array}$ \\
\hline
\end{tabular}

\section{Teacher Interactions}

Interactions between children and teachers that were coded include positive engagement, guided instruction, and non-compliance. Table 2 includes the operational definitions. 


\section{Table 2}

Coding Categories for Child-Teacher Interactions

\begin{tabular}{|l|l|l|}
\hline $\begin{array}{l}\text { Child-Teacher } \\
\text { Interaction Type }\end{array}$ & Key Features & Observational/Behavioral Cues \\
\hline $\begin{array}{l}\text { Positive engagement } \\
\text { (positive interaction) }\end{array}$ & $\begin{array}{l}\text { Child is interacting with } \\
\text { the teacher with positive } \\
\text { affect and is actively } \\
\text { responding }\end{array}$ & $\begin{array}{l}\text { The child is having a } \\
\text { conversation with the teacher } \\
\text { about the art task }\end{array}$ \\
\hline $\begin{array}{l}\text { Guided instruction } \\
\text { (positive interaction) }\end{array}$ & $\begin{array}{l}\text { Child receives hands-on } \\
\text { assistance from the } \\
\text { teacher for completing } \\
\text { the task }\end{array}$ & $\begin{array}{l}\text { The teacher is showing the child } \\
\text { how to do the art task by guiding } \\
\text { and being hands-on }\end{array}$ \\
\hline $\begin{array}{l}\text { Non-compliance } \\
\text { (negative interaction) }\end{array}$ & $\begin{array}{l}\text { Child disobeys and does } \\
\text { not follow instructions } \\
\text { Negative affect }\end{array}$ & $\begin{array}{l}\text { The child argues with the teacher } \\
\text { about completing the task }\end{array}$ \\
\hline
\end{tabular}

\section{Procedure}

Institutional Review Board approval (IRB-2019-473) and site permission were secured.

Children were invited to participate in the study via a packet which contained a description of the study and a permission form for parents to provide child participation. The packets were sent home with the child with instructions to send the form back with the child after it was signed if they wished to participate.

Observations of the participating children's behavior were collected by approximately 15 researchers each week during the 12-week program. The researchers went through a training that involved understanding what behavior falls under what category and had the opportunity to practice using the application before starting to collect data. Data collection happened once a week for six weeks in the Fall and once a week for six weeks in the Spring. Instructors affiliated with the Illinois Art Station provided art education to children in the preschool once a week. Each session included two to three classes of students, with approximately 55 students total. The 
teacher to child ratio was approximately one Illinois Art Station instructor or preschool teacher per 10 children.

Illinois Art Station is an independent nonprofit organization that teaches art classes around the community. With the current study, Illinois Art Station came into a local preschool once a week for 12 weeks to provide art lessons that focused on social and emotional topics. Illinois Art Station art instructors taught the art lesson for the day and ensured all the students understood and participated in the art project each week. These instructors are different from the preschool teachers that work for the school.

The same instructor provided the lessons throughout the entire 12-week program for each session. The same children participated throughout the 12 weeks. They were all brought to the gymnasium in the preschool where the art classes took place. Each child was given an ID number and their teacher-child and peer interactions data was tracked from week to week. The instructor began each 30-minute lesson by providing an overview of that day's art lesson while the children were sitting in the center of the room on a rug. For example, children were asked to create a monster face using a variety of art media, including felt shapes on a felt board. The students then were separated by class and placed in assigned seats based on their ID number at different tables and worked to create their own monster face for approximately 20 minutes during which time behaviors were live coded by trained research assistants. Each session included up to 55 preschoolers.

Research assistants were assigned to record up to 13 children's behaviors. While the children were creating their own art project, research assistants collected behavioral data. These research assistants walked from student to student and were instructed to quickly record whether they observed peer and teacher interactions. If an interaction from the lists presented in Tables 1 
and/or 2 was observed, the research assistant would choose the type of interaction observed and move to the next child. Each observation took approximately 2-5 seconds. Thus, research assistants recorded samples of interactions between peers and teachers approximately 8 to 10 times for each child during each 20-minute class.

The data included six weeks of classes in the Fall and six weeks of classes in the Spring. Each child had around 48 observational data in the Fall and again in the Spring. In order to control for differences in frequency, raw data were converted to proportions based on how many data points were coded for each student. The proportions were calculated based on how many of each type of peer interaction and teacher-child interaction each student exhibited divided by the total number of observations for that child. For example, if a research assistant only coded ten instances of peer observational data throughout the semester; the proportion of each behavior would be out of ten. The sum across the two positive categories was divided by the total frequency of observations. This method was used to compute a proportion for the positive teacher-child interactions and positive peer interactions. For the negative teacher-child interaction and negative peer interaction, the total negative category was divided by the total frequency of observations. See below for more details.

Observational data was categorized into different behaviors. These behaviors were selected based on previous work that centered around teacher-child and peer interactions (BarTal et al., 1982; Williford et al, 2013). These categories and behaviors were also informed by social learning theory because all of the specific behaviors and their categories all deal with teachers influencing or modeling to students or peers doing the same to other students. These categories were split into positive or negative behaviors. Behaviors were categorized as positive if they involved interacting with peers or teachers in a positive affect or being sociability 
(Williford et al., 2013). In the current study, the positive teacher-child behaviors included positive engagement and guided instruction. Positive engagement and guided instruction were combined because they each involve students having the opportunity to be social with their teachers in a positive way. The positive peer behaviors included working together and helping. Working together and helping were combined because they also involve students having the opportunity to be social with their peers in a positive way. Both the positive teacher-child and peer interactions were analyzed together and not separately because of the limited about of interactions coded during the art class. Behaviors were categorized as negative if they involved interacting with peers or teachers in a negative affect or using aggression (Williford et al., 2013). In the current study, the negative peer behavior included conflict. One positive teacher-child behavior proportion and one positive peer behavior proportion was calculated for each participant per semester. One negative teacher-child behavior proportion and one negative peer behavior proportion was calculated for each participant per semester. Each proportion was calculated by taking the total frequency of either positive behaviors or negative behaviors throughout the semester divided by the total frequency of behaviors taken throughout the semester. For example, Participant 1 had four positive engagements with their teacher throughout the semester and three guided instructions throughout the semester, those frequencies would be combined to get a total of seven positive teacher-child interactions for the semester. The total numbers of behaviors Participant 1 had with the teacher was 11 throughout the semester. This total includes all the behaviors Participant 1 had with the teacher not just positive behaviors. The positive teacher-child interaction proportion then for Participant 1 would be 0.636 for the fall, which is seven divided by 11 . 
Inter-rater reliability was collected once a week for 6 weeks by two research assistants independently coding data on the same participant at the same time using separate iPads. Only a select number of researchers were involved with reliability coding. While one research assistant was coding observational data on their 13 children, another research assistant was also coding observational data on the same 13 children at the same time. The research assistant doing the reliability coding would keep up with the other research assistant so they were coding the same child at roughly the same time.

A reliability analysis was conducted by calculating the exact percentage agreement between raters for all codes they both scored. Raters agreed on 66 out of 178 codes yielding an exact percentage agreement of $37 \%$. The teacher-child reliability proportion was 0.30 , and the peer reliability proportion was 0.43 . The combined reliability proportion for both teacher-child and peer was 0.37 . A Cohen's kappa also was conducted given the categorical nature of coding. Kappa takes into account the relative frequency across codes and corrects for chance agreement. The Cohen's kappa was 0.50 for the peer interactions. The Cohen's kappa was 0.16 for teacherchild interactions. A reason for the better reliability for peer interactions over teacher interactions could be due to the thin boundary between positive engagement and guided instruction. Coders could have seen guided instruction as positive engagement because a child could have positive conversations with the teacher while the teacher is helping them with the art project. These interrater reliability analyses indicate that the coding system was not reliable. These low reliability proportions could be partially explained by the fact that each coder could have interpreted a child's behavior differently. Another reason could be how quickly each child is moving from one interaction to the next with both their teacher and peers. For example, one coder could have coded a participant exhibiting focused attention on the teacher, but by the time the second coder 
noticed the child could have stopped displaying that behavior with the teacher. Lastly, another reason could be due to the timing of coding not being controlled. The two coders may have been observing behaviors at different times. The low reliability will hinder strong conclusions from the analyses. 


\section{CHAPTER III: RESULTS}

A moderation regression was conducted to examine the relationship between positive teacher-child interactions, positive peer interactions, and gender. My first research question was: Do positive teacher-child interactions in the fall predict positive peer interactions in the spring? My hypothesis was not supported. The predictor variable, positive teacher-child interactions, was the combined proportion of positive engagement and guided instruction. The outcome variable, positive peer interactions, was the combined proportion of working together and helping. The moderator variable was gender and was entered into the model along with positive teacher-child interactions and positive peer interactions. When gender was included as the moderator in the model, positive teacher-child interactions in the fall did not predict a significant variance in positive peer interactions in the spring, $\beta=0.22, R^{2}=.05, F(3,62)=0.97, p=.41$. Table 3 shows the beta weights of the regression analysis.

A moderation regression was conducted to examine the relationship between negative teacher-child interactions, negative peer interactions, and gender. My second research question: Do negative teacher-child interactions in the fall predict negative peer interactions in the spring? My hypothesis was not supported. The predictor variable, negative teacher-child interactions, was the proportion of non-compliance. The outcome variable, negative peer interactions, was the proportion of conflict. The moderator variable was gender and was entered into the model along with negative teacher-child interactions and negative peer interactions. When gender was included as the moderator in the model, negative teacher-child interactions in the fall did not predict a significant variance in negative peer interactions in the spring, $\beta=0.07, R^{2}=.01, F(3$, $64)=0.27, p=.85$. Table 4 shows the beta weights of the regression analysis. 
A moderation regression was conducted to examine the relationship between positive peer interactions in the fall, positive peer interactions in the spring, and gender. My third research question: Do positive peer interactions in the fall predict positive peer interactions in the spring? My hypothesis was not supported. The predictor variable, positive peer interactions in the fall, was the combined proportion of working together and helping. The outcome variable, positive peer interactions in the spring, was the combined proportion of working together and helping. The moderator variable was gender and was entered into the model along with positive peer interactions in the fall and positive peer interactions in the spring. When gender was included as the moderator in the model, positive peer interactions in the fall did not predict a significant variance in positive peer interactions in the spring, $\beta=0.08, R^{2}=.02, F(3,62)=$ $0.40, p=.75$. Table 5 shows the beta weights of the regression analysis.

A moderation regression was conducted to examine the relationship between negative peer interactions in the fall, negative peer interactions in the spring, and gender. My fourth research question: Do negative peer interactions in the fall predict negative peer interactions in the spring? My hypothesis was supported. The predictor variable, negative peer interactions in the fall, was the proportion of conflict. The outcome variable, negative peer interactions in the spring, was the proportion of conflict. The moderator variable was gender and was entered into the model along with negative teacher-child interactions and negative peer interactions. When gender was included as the moderator in the model, negative peer interactions in the fall did predict a significant variance in negative peer interactions in the spring, $\beta=0.34, R^{2}=.15, F(3$, $64)=3.74, p=.02$. Table 6 shows the beta weights of the regression analysis.

An independent samples t-test was conducted to examine gender differences in positive and negative teacher-child and peer interactions. Boys were coded at 0 and girls were coded as 1 . 
My fifth research question was: Are there gender differences in how children interact with both their teachers and peers? My hypothesis was not supported. There was not a significant difference in positive teacher-child interactions for boys $(M=13.00, S D=6.83)$ and girls $(M=$ $10.46, S D=6.01), t(66)=1.63, p=.53$. Figure 1 shows the independent samples t-test analysis. There was not a significant difference in positive peer interactions for boys $(M=4.06, S D=$ 2.73) and girls $(M=3.97, S D=3.53), t(66)=0.12, p=.47$. Figure 2 shows the independent samples t-test analysis. There was not a significant difference in negative teacher-child interactions for boys $(M=1.13, S D=1.56)$ and girls $(M=0.68, S D=1.83), t(66)=1.09, p=.48$. Figure 3 shows the independent samples t-test analysis. There was not a significant difference in negative peer interactions for boys $(M=0.22, S D=0.56)$ and girls $(M=0.24, S D=0.76), t(66)$ $=-0.11, p=.75$. Figure 4 shows the independent samples t-test analysis. There was not a significant difference in total teacher-child and peer interactions for boys $(M=18.42, S D=7.98)$ and girls $(M=15.35, S D=7.54), t(66)=1.63, p=.68$. Figure 5 shows the independent samples t-test analysis.

Spearman correlations were conducted to examine the relations between the outcome variables (i.e., the proportional measures and gender). Results indicated that there was a significant negative association between gender and negative teacher-child interactions in the spring, $r(68)=-.28, p=.02$. Boys show fewer negative teacher-child behaviors compared to girls. Negative peer behaviors in the fall were positively correlated with negative peer behaviors in the spring, $r(68)=.30, p=.01$. This similar pattern can be seen in the regression analysis where children model negative behaviors to their peers. The positive teacher-child behaviors in the fall showed fewer negative teacher-child behaviors during the same time period, $r(68)=-.28$, $p=.02$. Children who showed more positive teacher-child behaviors in the fall would have fewer 
negative teacher-child behaviors during that time. There was a significant positive association between positive teacher-child interactions in the fall and negative teacher-child interactions in the spring, $r(68)=.33, p=.01$. Children who show more positive peer behaviors in the spring also show more positive teacher-child behaviors during that time, $r(68)=.27, p=.03$. Lastly, children who show more negative peer behaviors in the spring also show more negative teacherchild behaviors during that time, $r(68)=.25, p=.04$. Children who behave poorly with their peers in the spring would be more likely to behave poorly with their teachers as well. Table 7 shows the correlations and ranges for the variables of interest. 


\section{CHAPTER IV: DISCUSSION}

This study set out to demonstrate the extent to which the proportion of interactions and the positive or negative connotation of the interactions that preschool children had with teachers predicted social-emotional relations with peers. I hypothesized that the proportion of teacher interactions as positive engagement and guided instruction in the fall would predict the proportion of peer interactions as working together and helping in the spring. It was found that positive teacher-child interactions in the fall did not predict positive peer interactions in the spring. This result could be due to a number of different reasons. Past research would indicate that children's positive relationship with their teachers and how teachers model behavior would result in more positive interactions with their peers (Farmer et al., 2011; Graves Jr. \& Howes, 2011; Rudasill et al., 2013; Williford et al., 2013). The current finding could be due to the size of the sample or method of examining these positive teacher-child and peer interactions. Past research observed these interactions in a natural setting, whereas the current study observed the interactions during a controlled program and setting. Other research also used teacher-reports to examine teacher-child and peer interactions. The current study did not utilize these methods of data collection. In addition to these reasons, children may not have had the opportunity to engage in these positive interactions during the 12-week program. The students were assigned seats and if the student was not sitting by a familiar peer, they may have been less likely to interact with them. The activities during the 12-week program could have also made it more difficult for students to interact with their peers in general. Collecting data while children are in their classroom compared to a controlled setting might result in seeing more behaviors performed by the participants. 
I hypothesized that the proportion of teacher interactions as non-compliance in the fall would predict the proportion of peer interactions as conflict in the spring. It was found that negative teacher-child interactions in the fall did not predict negative peer interactions in the spring. Past research would indicate that teacher-child conflict is a significant and consistent predictor of teacher-rated conflict problems and peer social skills (Graves Jr. \& Howes, 2011). Other research has also found that conflict with teachers and peers was highly related (Williford et al., 2013). As stated above, the current finding could be due to the small sample size, the controlled environment, and the lack of teacher reports. In addition, the finding could be explained by the fact that little conflict was seen altogether during the 12 weeks. The reason for the little conflict could be from a new teacher being around the students and the students being told to be on their best behavior. The preschool that we collected data from also utilizing a positive behavior intervention and support system to help the students appropriately behave when interacting with adults and peers.

I hypothesized that the proportion of peer interactions as working together and helping in the fall would predict the proportion of peer interactions as working together and helping in the spring. It was found that positive peer interactions in the fall did not predict positive peer interactions in the spring. Past research would indicate that peer play represents a primary context in which preschool children acquire and express peer social competencies (Coolahan et al., 2000). Other research has stated that children model appropriate behavior for their peers (Snyder, Horsch, \& Childs, 1997). As with some of the previous findings, the result could be due to the fact that the sample size was low or because of the controlled setting. As mentioned above, the students might have had the opportunity to have or model appropriate behaviors. If the child was focused on the task for that day, they might not have wanted to interact with their peers or if 
the student was not sitting by their friends, they might not have wanted to interact with anyone sitting around them.

I hypothesized that the proportion of peer interactions as conflict in the fall would predict the proportion of peer interactions as conflict in the spring. It was found that negative peer interactions in the fall did predict negative peer interactions in the spring. My supported hypothesis was similar to results found by Snyder et al (1997) where aggressive children affiliate with similarly aggressive peers and these peer relationships model aggressive behaviors. Other research states that repeated exposure to these negative peer interactions during play are important experiences that impact children's social development (Coolahan et al., 2000). This finding could be explained by the fact that once children see negative interactions modeled to them by their peers, they might be more inclined to also engage in problem behaviors. Since the preschool we collected data at uses a program to help children use appropriate behavior, children might not have some opportunities to engage in these problem behaviors within their usual settings and routines. With a new setting, children might test the new teacher's limits and see what they can get away with when interacting with each other. When one student behaves poorly, they are modeling those inappropriate behaviors to their peers. Over time, the students might gain more confidence and want to continue to engage in these negative interactions.

I hypothesized that girls would have more positive teacher-child interactions as positive engagement and guided instruction and positive peer interactions as working together and helping than would boys; and that boys would have more negative teacher-child as noncompliance and negative peer interactions as conflict than would girls. No significant gender differences were found for positive and negative teacher-child and peer interactions. Past research would indicate that girls tend to be more cooperative in their interactions with peers, 
whereas boys tend to be more focused on establishing dominance in their interactions (Maccoby, 1998). Other research has found that teachers tend to have closer and less conflictual relationships with girls compared to boys (Baker, 2006). As stated above, the current finding could be due to the fact that teacher-reports were not utilized. As also stated above, another reason could be because of who each student was sitting by. Boys could have been better behaved if they were not sitting next to a friend or another child they have had issues with in the past. For girls, they might be less inclined to have any interactions if they are not sitting next to someone they know. The 12-week program could have also had activities where the children did not have the opportunities to engage in as many interactions as they would have in a natural setting. The program the preschool uses to teach the students appropriate behavior might also explain the lack of conflict seen by students towards their teachers.

One limitation of the current study is the size of the sample. The sample size for the current study was only 68 young children. It is hard to generalize the findings with a sample size that is that small. A second limitation of the current study was the fact that the ages of the children were not collected. Applying the findings of the current study when it comes to age differences would be hard without that data. Another limitation of the current study is the length of data collection. Past research observed children over a period of 3 years (Howes et al., 1994), while the current study only observed children over a period of 12 weeks. Changes in how children interact with their teachers and peers might only be present and observed over a longer period of time. Another limitation is variability of data collection. Multiple trained research assistants collected data during the study so they could interpret the behaviors in different ways and the rate of their data collection could vary. Using a smaller set of research assistants who complete longer training on coding would be helpful. Another major limitation of the study is the 
low inter-rater reliability found. There was only a $37 \%$ agreement on the codes. This low interrater reliability could be explained by the fact that each coder could have interpreted a child's behavior differently. More clearly defined coding categories could help rectify this problem. Another reason could be how quickly each child is moving from one interaction to the next with both their teacher and peers. Lastly, another reason could be due to the timing of coding not being controlled. With this, the two coders may have been observing behaviors at different times. Using momentary time sampling with defined timing intervals would help overcome these limitations. Researchers could use a timer application so they know when their time is up with one child before moving on to the next child to collect observations. One last limitation could be the study being correlational in nature. No casual conclusions can be drawn do to the fact that everyone participated in the program. Future work could focus on a group of children getting the art program while another group of children do not receive the art program and participate in their regular school work.

A future direction this research could take would be doing a longer longitudinal study and having a larger sample of children. A larger sample size could be around 200 children and this sample size could help to better generalize the findings. Children's social-emotional development such as how they interact with teachers and peers could by looked at as children progress from preschool through the end of high school. Having a longer longitudinal study would have problems on its own with having to worry about the retention rate of the participants and confounding variables as the students get older. If a shorter longitudinal study was done, focusing on preschool through elementary school would show how behaviors children display with teachers and peers in preschool could affect how they interact with these individuals as they grow older and get into elementary school. Social-emotional skills are not only related to 
emotion regulation and socialization with teachers and peers, but overall school adjustment. Another future direction could be to collect parent and teacher reports and see how they differ. These parent and teacher reports could help us better understand how children are interacting with their peers and teachers outside of the art program. These parent and teacher reports could also be used to examine self-regulation skills in children. Past research has utilized teacher reports to examine teacher-child and peer interactions (Rudasill et al., 2013; Howes et al., 1994). To address the reliability and coding problems, the boundaries of what counts for each teacherchild and peer interaction could be more detailed so coders are not reporting different behaviors and questioning what a behavior would fall under a certain category. Future studies could utilize the same categories and behaviors, but the boundaries would be more detailed to avoid any confusion between the coders. Additional training could also be utilized so the coders are aware of the different behaviors that could be present and how to time out each rotation to get a similar amount of behaviors coded. Training to criterion using a pre-defined set of codes could also be present in future studies. Lastly, a time sampling approach would help with the timing of the coding not being controlled. Coders would use a timed approach for how long they can spend with each student so it is consistent over all the coders.

Future questions could also be asked with the given data. One question that could be asked: is there an age effect with the development of these teacher-child and peer interactions? In the current study, age was not collected for each participant, but future studies could collect age and analyses could be done with looking at age differences. Another question that could be asked: are there differences with how students interact with teachers depending on the gender of the teacher? In the current study, gender of the teachers were not collected, but future research could focus on how children behave based off what gender the teachers are. A third question that 
could be asked in future studies: are there racial differences when it comes to the development of teacher-child and peer interactions. The current study did not collect the race/ethnicity of each participant, but future studies could include this information on the demographic sheet so analyses can be done to look at these differences. Lastly, another question that could be asked: are there differences in how children interact with their teachers and peers depending on if they are typically developing compared with children that have developmental disabilities? There were both typically developing children and children with developmental disabilities that participated in the program, but analyses was not done in the current study to look at these differences.

The findings provided insight about the stability of negative peer interactions for young children. Negative peer interactions relate to children's school adjustment. Past research has showed that children who negatively engage with their peers showed fewer gains in their selfregulation skills which deals with school adjustment (Williford et al., 2013). Children also model these problem behaviors to their peers (Snyder, Horsch, \& Childs, 1997). When children behave in an inappropriate way in school, their peers pick up on these behaviors and model after each other. The knowledge of the effect children have on their peers' social and emotional development is important for child-friendly settings. By understanding how children interact and model behaviors to their peers, one could intervene before these inappropriate behaviors become consistent over time. If children continue to model negative behaviors, they and their peers could progress in the type of problem behaviors they are doing. As children get older, peer influences are stronger over teacher influence. These strong negative influences could lead to major behavior problems outside of the negative interactions seen in this study. A prevention focus could also help with these negative behaviors starting in young children. Having prevention 
programs that involve teaching social skills and self-regulation to children could help teach them to use appropriate behaviors with their teachers and peers. Overall, the current study provides an analysis of the behaviors children demonstrate with teachers and peers and the findings demonstrate the influence negative peer interactions have on children. 


\section{REFERENCES}

Baker, J. A. (2006). Contributions of teacher-child relationships to positive school adjustment during elementary school. Journal of School Psychology, 44, 211-229.

Bandura, A. (1976). Social Learning Theory. Englewood Cliffs, NJ: Prentice Hall.

Bar-Tal, D., Raviv, A., \& Goldberg, M. (1982). Helping behavior among preschool children: An observational study. Child Development, 53(2), 396-402.

Barth, J. M., Dunlap, S. T., Dane, H., Lochman, J. E., \& Wells, K. C. (2004). Classroom environment influences on aggression, peer relations, and academic focus. Journal of School Psychology, 42(2), 115-133.

Booren, L. M., Downer, J. T., \& Vitiello, V. E. (2012). Observations of children's interactions with teachers, peers, and tasks across preschool classroom activity settings. Early Education \& Development, 23(4), 517-538.

Brouillette, L. (2010). How the arts help children to create healthy social scripts: Exploring the Perceptions of Elementary Teachers. Arts Education Policy Review. 111, 16-24.

Capuzzi, D., \& Stauffer, D. M. (2016). Early childhood: emotional and social development. In D. Capuzzi \& M. D. Stauffer (Eds.), Human Growth and Development Across the Lifespan: Applications for Counselors. (1 ${ }^{\text {st }}$ ed., pp. 217-248). Hoboken, NJ: John Wiley.

Coolahan, K., Fantuzzo, J., Mendez, J., \& McDermott, P. (2000). Preschool peer interactions and readiness to learn: Relationships between classroom peer play and learning behaviors and conduct. Journal of Educational Psychology, 92(3), 458-465.

Davis, D. W., Logsdon, M. C., Myers, J., Ryan, L., Evanow, K., \& Hancock, M. (2016). Development and initial testing of the parent beliefs about early childhood socialemotional development instrument. Archives of Psychiatric Nursing, 30(4), 492-496. 
Denham, S. A., Bassett, H. H., Mincic, M., Kalb, S., Way, E., Wyatt, T., \& Segal, Y. (2012). Social-emotional learning profiles of preschoolers' early school success: a personcentered approach. Learning and Individual Differences, 22(2), 178-189.

Erdfelder, E., Faul, F., \& Buchner, A. (1996). GPOWER: A general power analysis program. Behavior research methods, instruments, \& computers, 28(1), 1-11.

Ewing, A. R., \& Taylor, A. R. (2009). The role of child gender and ethnicity in teacher-child relationship quality and children's behavioral adjustment in preschool. Early Childhood Research Quarterly, 24(1), 92-105.

Farmer, T. W., Lines, M. M., \& Hamm, J. V. (2011). Revealing the invisible hand: The role of teachers in children's peer experiences. Journal of Applied Developmental Psychology, 32(5), 247-256.

Fredricks, J. A., Blumenfeld, P. C., \& Paris, A. H. (2004). School engagement: Potential of the concept, state of the evidence. Review of Educational Research, 74(1), 59-109.

Garner, W. P., \& Estep, M. K. (2001). Emotional competence, emotion socialization, and young children's peer-related social competence, Early Education and Development, 12(1), 2948.

Graves Jr, S. L., \& Howes, C. (2011). Ethnic differences in social-emotional development in preschool: The impact of teacher child relationships and classroom quality. School Psychology Quarterly, 26(3), 253-263.

Greene, M. L., \& Sawilowsky, S. (2018). Integrating the arts into head start classrooms produced positive impacts on kindergarten readiness. Early Childhood Research Quarterly, 28, 337-346. 
Hamre, B. K., \& Pianta, R. C. (2001). Early teacher-child relationships and the trajectory of children's outcomes through eighth grade. Child Development, 72, 625-638.

Howes, C., Hamilton, C., \& Matheson, C. (1994). Children's relationships with peers: Differential associations with aspects of the teacher-child relationship. Child Development, 65(1), 253-263.

Howe, C., \& McWilliam, D. (2001). Peer argument in educational settings: Variations due to socioeconomic status, gen- der, and activity context. Journal of Language and Social Psychology, 20(1-2), 61-80.

Immordino-Yang, M. H., Darling-Hammond, L., \& Krone C. R. (2019) Nurturing nature: How brain development is inherently social and emotional, and what this means for education. Educational Psychologist, 54(3), 185-204.

Janus, M., Duke, E., Brinkman, S., Dunkelberg, E., Chianca, T., \& Marino, E. (2014). Socioemotional development and its correlates among 5-year-old children in Peru and Brazil. Journal of Latino-Latin American Studies, 6(1), 40-53.

Katz, L. G., \& McClellan, D. E. (1991). The teacher's role in the social development of young children. Urbana, IL: ERIC Clearinghouse on Elementary and Early Childhood Education.

Maccoby, E. E. (1998). The Two Sexes: Growing Up Apart, Coming Together. Cambridge, MA: Belknap Press/Harvard University Press.

Newton-Fisher, N.E. (2012). Animal Behavior Pro (Version 1.5) [Mobile application software].

O’Connor, E. E., Dearing, E., \& Collins, B. A. (2011). Teacher-child relationship and behavior problem trajectories in elementary school. American Educational Research Journal, 48(1), 120-162. 
Parten, M. B. (1932). Social Participation among Preschool Children. Journal of Abnormal and Social Psychology, 27, 243-269.

Piaget, J. (1985). Play, Dreams, and Imitation in Children. New York, NY: Norton.

Raičevič, J., Nikolic, S., Vlasta, L., \& Saračevič, M. (2017). Teachers and social learning as a factor of modern educational competencies. Bulgarian Journal of Science \& Education Policy, 11(2), 233-245.

Raver, C. C. (2002). Emotions matter: making the case for the role of young children's emotional development for early school readiness. Social Policy Report, 16, 3-18.

Rubin, K. H., \& Maioni, T. L. (1975). Play preference and its relationship to egocentrism, popularity, and classification skills in preschoolers. Merrill-Palmer Quarterly, 21, 171179.

Rubin, K. H. (1977). Play behaviors of young children. Young Children, 32(6), 16-24.

Rudasill, K. M., Niehaus, K., Buhs, E., \& White, J. M. (2013). Temperament in early childhood and peer interactions in third grade: The role of teacher-child relationships in early elementary grades. Journal of School Psychology, 51(6), 701-716.

Smilansky, S. (1968). The effects of sociodramatic play on disadvantaged children: preschool children. Hoboken, NJ: John Wiley.

Snyder, J., Horsch, E., \& Childs, J. (1997). Peer relationships of young children: Affiliative choices and the shaping of aggressive behavior. Journal of Clinical Child Psychology, 26(2), 145-156.

Thompson, R. A. (1991). Emotional regulation and emotional development. Educational Psychology Review, 3(4), 269-307. 
Trawick-Smith, J., \& Dziurgot, T. (2011). 'Good-fit'teacher-child play interactions and the subsequent autonomous play of preschool children. Early Childhood Research Quarterly, 26(1), 110-123.

Wilcox-Herzog, A., \& Kontos, S. (1998). The nature of teacher talk in early childhood classrooms and its relationship to children's play with objects and peers. Journal of Genetic Psychology, 159, 65-109.

Williford, A. P., Maier, M. F., Downer, J. T., Pianta, R. C., \& Howes, C. (2013). Understanding how children's engagement and teachers' interactions combine to predict school readiness. Journal of Applied Developmental Psychology, 34(6), 299-309. 


\section{APPENDIX A: TABLES}

\section{Table 3}

Beta Weights for Gender, Positive Teacher-Child Interactions, and Positive Teacher-Child

Interactions $x$ Gender when Predicting Positive Peer Interactions

Model Non-standardized coefficient $\quad$ Standardized coefficient $\quad t \quad p$

\begin{tabular}{|c|c|c|c|c|c|}
\hline & B & Standard error & Beta & & \\
\hline (Constant) & -.09 & .34 & & -.27 & .79 \\
\hline Gender & -.26 & .45 & .11 & .88 & .38 \\
\hline $\begin{array}{l}\text { Positive } \\
\text { Teacher-Child }\end{array}$ & & & & & \\
\hline Interactions & -.04 & .06 & -.12 & -.74 & .46 \\
\hline $\begin{array}{l}\text { Positive } \\
\text { Teacher-Child }\end{array}$ & & & & & \\
\hline Interactions x Gender & .12 & .09 & .22 & 1.37 & .18 \\
\hline
\end{tabular}




\section{Table 4}

Beta Weights for Gender, Negative Teacher-Child Interactions, and Negative Teacher-Child

Interactions $x$ Gender when Predicting Negative Peer Interactions

\begin{tabular}{lllll} 
Model & Non-standardized coefficient & Standardized coefficient & $t$ & $p$ \\
\hline
\end{tabular}

\begin{tabular}{|c|c|c|c|c|c|}
\hline & B & Standard error & Beta & & \\
\hline (Constant) & -.01 & .004 & & -1.55 & .12 \\
\hline Gender & .002 & .01 & .04 & .32 & .75 \\
\hline $\begin{array}{l}\text { Negative } \\
\text { Teacher-Child }\end{array}$ & & & & & \\
\hline Interactions & -.04 & .07 & -.16 & -.62 & .54 \\
\hline $\begin{array}{l}\text { Negative } \\
\text { Teacher-Child }\end{array}$ & & & & & \\
\hline Interactions x Gender & .02 & .08 & .07 & .27 & .78 \\
\hline
\end{tabular}




\section{Table 5}

Beta Weights for Gender, Positive Peer Interactions in the Fall, and Positive Peer Interactions $x$ Gender when Predicting Positive Peer Interactions in the Spring

\begin{tabular}{|c|c|c|c|c|c|}
\hline \multirow[t]{2}{*}{ Model } & \multicolumn{2}{|c|}{ Non-standardized coefficient } & \multirow{2}{*}{$\frac{\text { Standardized coefficient }}{\text { Beta }}$} & \multirow[t]{2}{*}{$t$} & \multirow[t]{2}{*}{$p$} \\
\hline & $\mathrm{B}$ & Standard error & & & \\
\hline (Constant) & -.16 & .33 & & -.47 & .64 \\
\hline Gender & .46 & .45 & .13 & 1.01 & .32 \\
\hline $\begin{array}{l}\text { Positive } \\
\text { Peer }\end{array}$ & & & & & \\
\hline Interactions & -.06 & .13 & -.08 & -.44 & .66 \\
\hline $\begin{array}{l}\text { Positive } \\
\text { Peer }\end{array}$ & & & & & \\
\hline Interactions x Gender & .08 & .18 & .08 & .44 & .66 \\
\hline
\end{tabular}


Table 6

Beta Weights for Gender, Negative Peer Interactions in the Fall and Negative Peer Interactions

$x$ Gender when Predicting Negative Peer Interactions in the Spring

Model Non-standardized coefficient $\quad$ Standardized coefficient $\quad t \quad t \quad p$

\begin{tabular}{|c|c|c|c|c|c|}
\hline & B & Standard error & Beta & & \\
\hline (Constant) & -.01 & .004 & & -1.64 & .11 \\
\hline Gender & .001 & .01 & .03 & .24 & .82 \\
\hline $\begin{array}{l}\text { Negative } \\
\text { Peer }\end{array}$ & & & & & \\
\hline Interactions & .07 & .25 & .06 & .27 & .79 \\
\hline $\begin{array}{l}\text { Negative } \\
\text { Peer }\end{array}$ & & & & & \\
\hline Interactions x Gender & .48 & .30 & .34 & 1.59 & .12 \\
\hline
\end{tabular}




\section{Table 7}

Correlations Among Proportional Measures $(N=68)$

Measures

$\begin{array}{lllllllll}1 & 2 & 3 & 4 & 5 & 6 & 7 & 8 & 9\end{array}$

1. Gender $($ Boys $=0$, Girls $=1)$

2. Fall Peer Positive - -.19 ---

3. Fall Peer Negative $\quad-.02 \quad .09 \quad---$

4. Fall Teacher Positive $\quad-\quad-.14 \quad .21 \quad-.07 \quad$---

5. Fall Teacher Negative $\quad \quad-.11 \quad-.05 \quad-.14 \quad-.28 * \quad---$

$\begin{array}{llllllll}\text { 6. Spring Peer Positive } & & .09 & .02 & -.14 & .04 & .18 & \text {--- }\end{array}$

$\begin{array}{lllllllll}\text { 7. Spring Peer Negative } & -.02 & .14 & .30 * & .15 & -.15 & .02 & ---\end{array}$

8. Spring Teacher Positive $\quad \begin{array}{llllllllllll} & & -.09 & .13 & .02 & & .06 & .16 & .27 * & -.01 & ---\end{array}$

9. Spring Teacher Negative $\quad \begin{array}{lllllllllll} & \mathbf{- . 2 8} * & -.04 & .09 & \mathbf{. 3 3} * * & -.16 & -.08 & \mathbf{. 2 5} * & .10 & ---\end{array}$

$\begin{array}{llllllllll}M & .54 & 2.58 & .01 & 6.68 & .03 & 1.24 & .01 & 2.74 & .01\end{array}$

$\begin{array}{llllllllll}S D & .50 & 2.59 & .02 & 5.02 & .08 & 1.77 & .02 & 2.47 & .06\end{array}$

$\begin{array}{lllllllll}\text { Min. } & 0 & 0 & 0 & 0 & 0 & 0 & 0 & 0\end{array}$

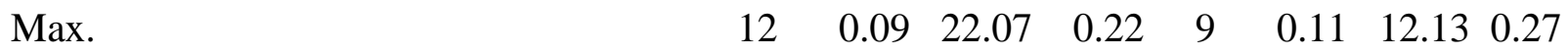

$* p<.05 ; * * p<.01$ 


\section{APPENDIX B: FIGURES}

\section{Figure 1}

Positive Teacher-Child Interactions for Boys and Girls

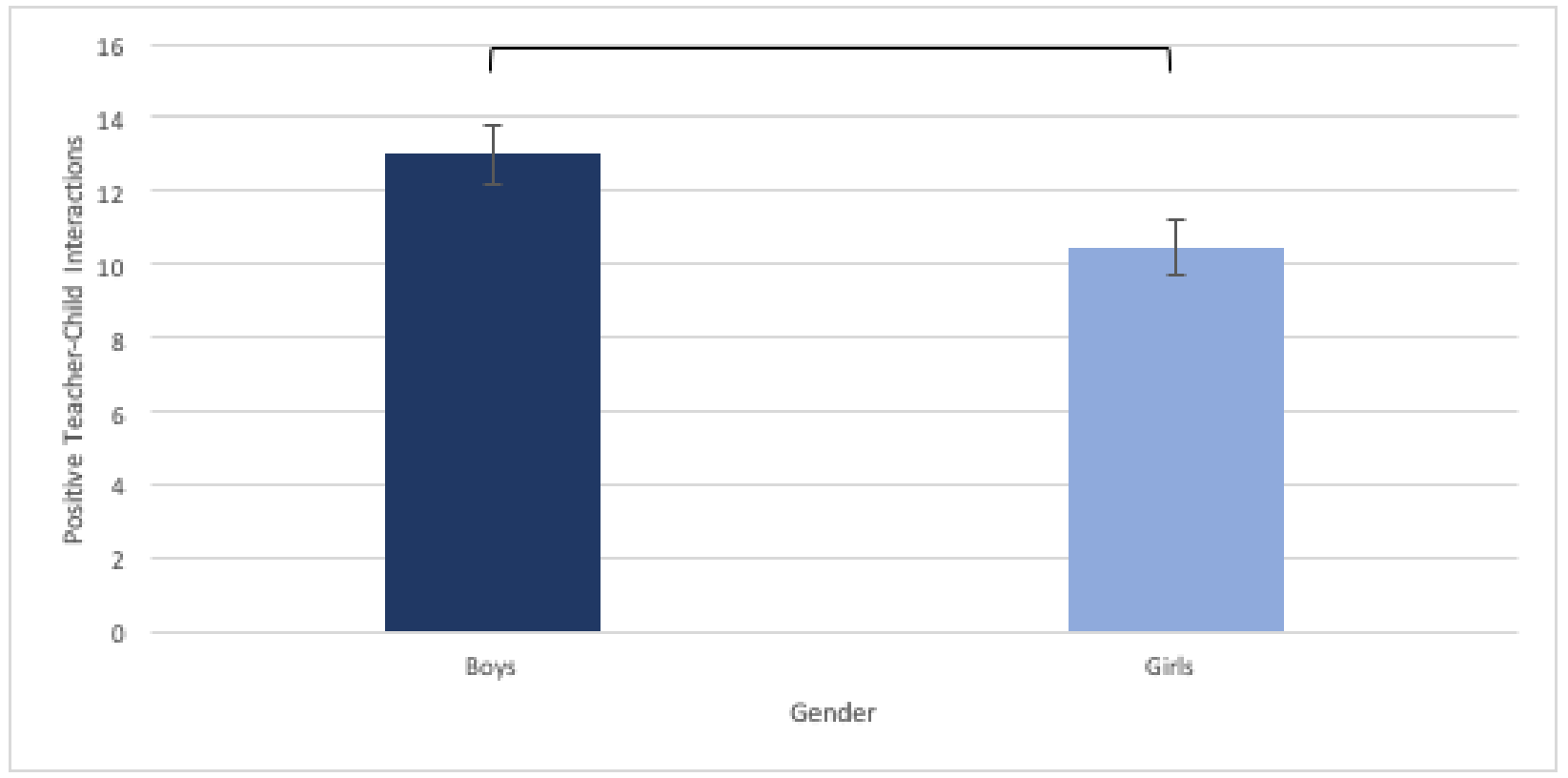


Figure 2

Positive Peer Interactions for Boys and Girls

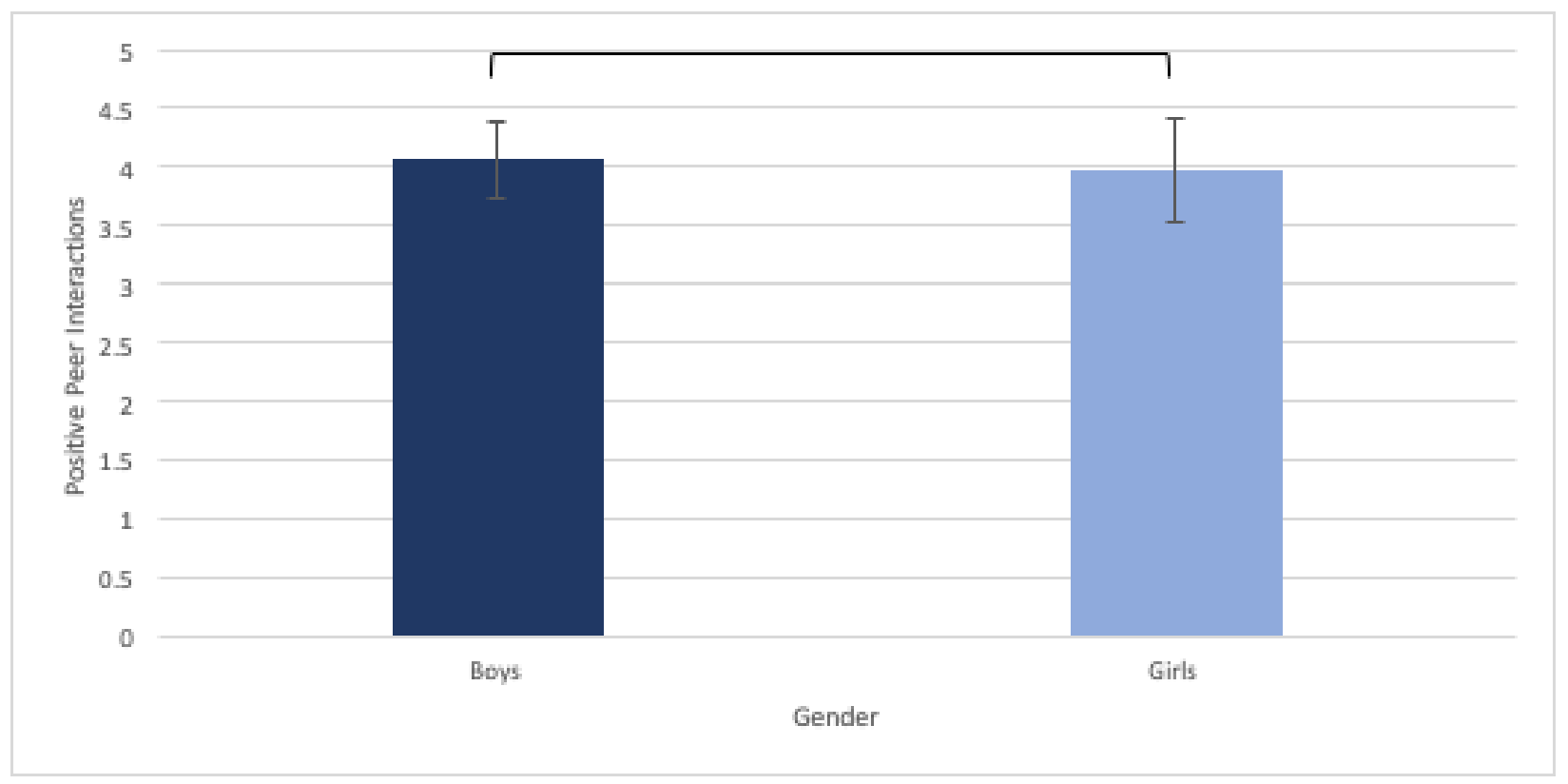




\section{Figure 3}

Negative Teacher-Child Interactions for Boys and Girls

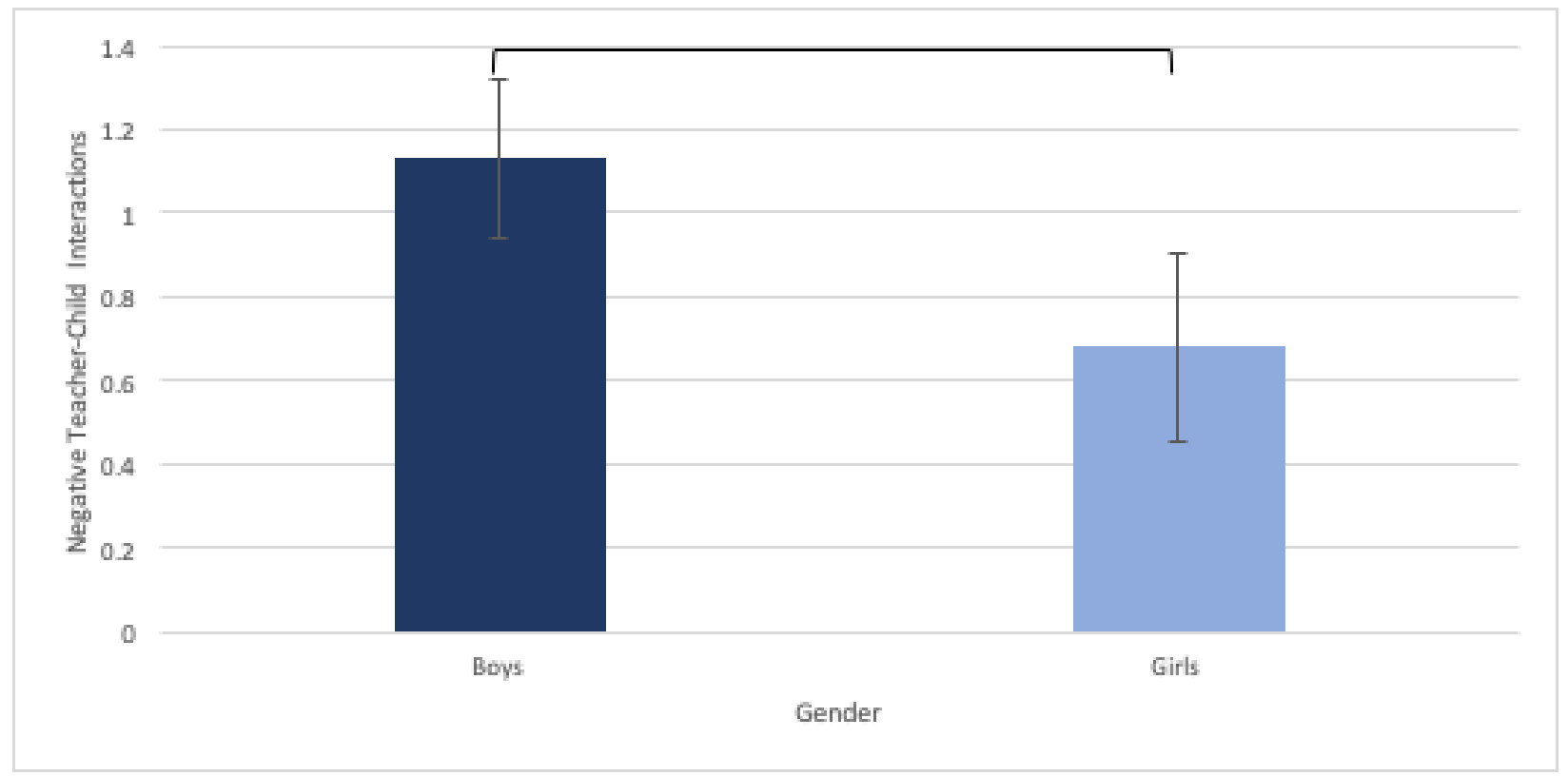




\section{Figure 4}

Negative Peer Interactions for Boys and Girls

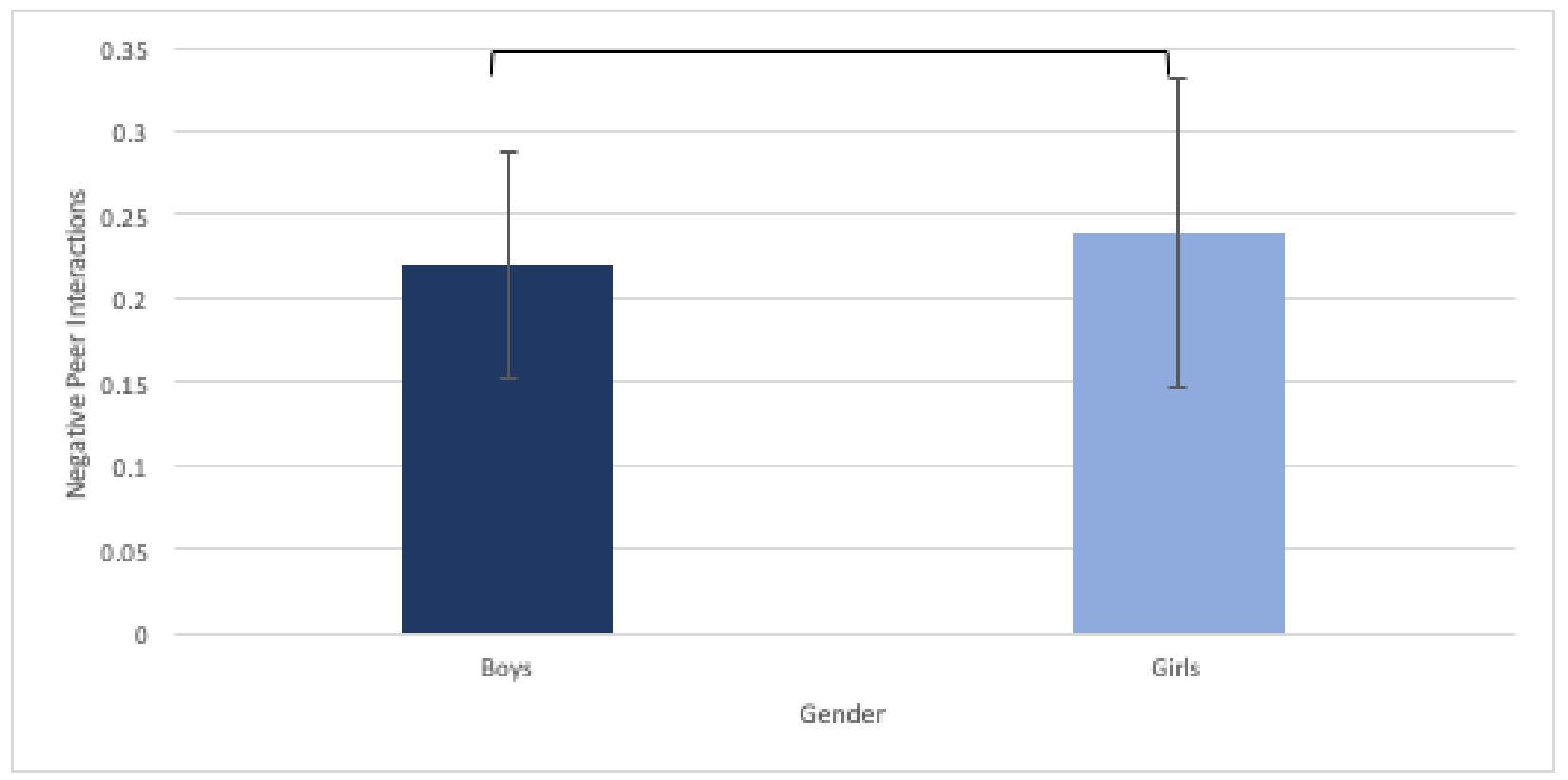




\section{Figure 5}

Total Teacher-Child and Peer Interactions for Boys and Girls

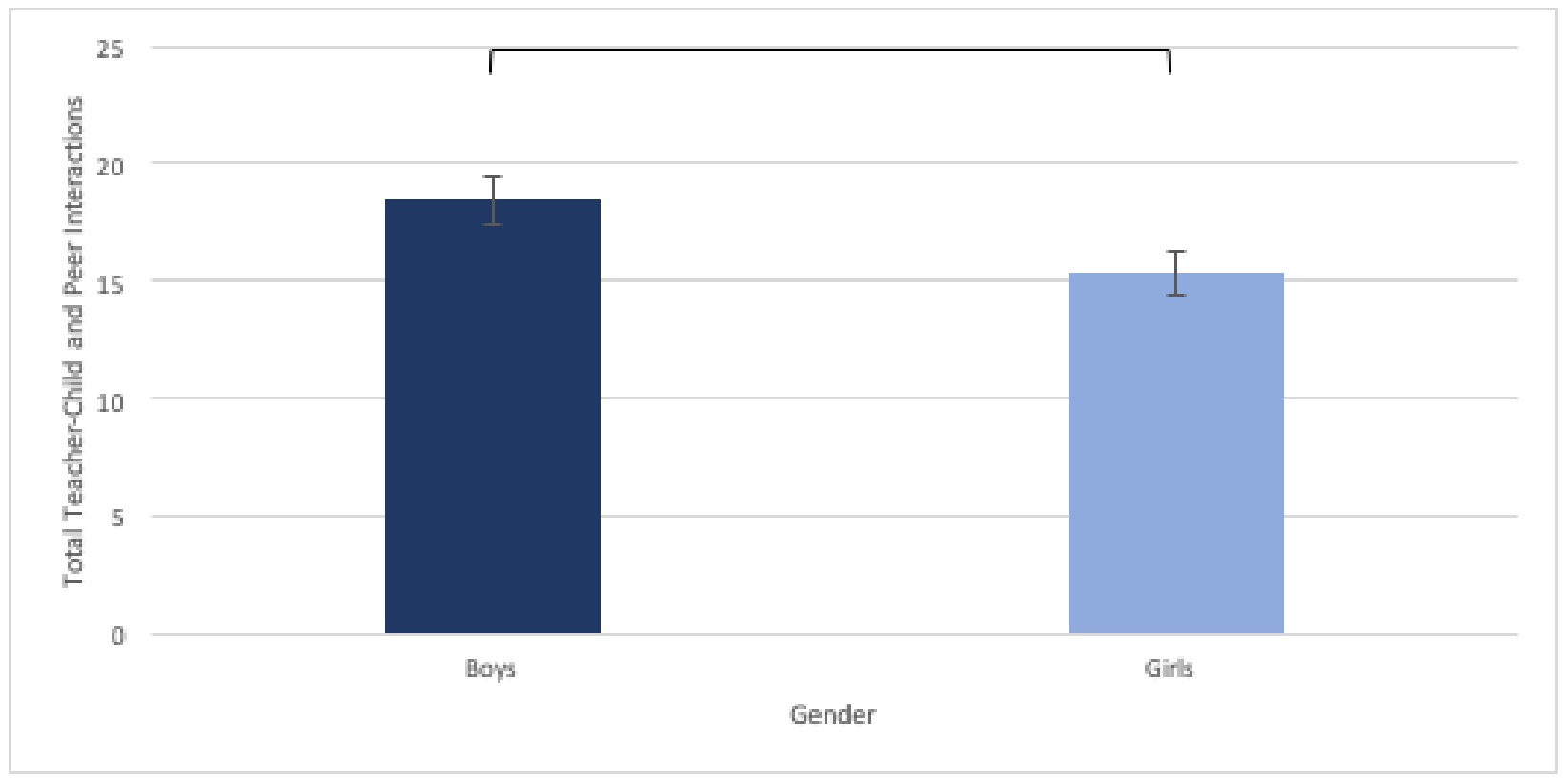

